immediate debriefs after the event would be very useful as well a better understanding of the multicultural religious rituals of the families.

Conclusion: Healthcare professionals support the grieving family but also recognize their inadequacy as supporters. Learning end-of-life skills is a matter of on-the-job training for most healthcare professionals. Personal experience of bereavement influences the way we manage end of life care professionally.

119

\section{EXPERIENCES OF GRIEF BY PEDIATRIC INTENSIVE CARE NURSES IN PADUA UNIVERSITY HOSPITAL: AN EXPLORATORY STUDY}

D. Tirelli ${ }^{1}$, I. de Barbieri², C. Zaggia ${ }^{2}$

${ }^{1}$ Casa di Cura 'Città di Udine', Udine, ${ }^{2} T e r a p i a$ Intensiva Pediatrica, Azienda Ospedaliera di Padova, Padova, Italy

Background: Nurses in Pediatric Intensive Care Units (PICU) are daily exposed to the suffering and death of their patients. Often the emotional burden may become unbereable, dysfunctional responses may arise and reflect negatively on patients' care.

Aim: To explore emotions and personal, social and professional consequences experienced by nurses working in PICU. Support currently available and the need for specialistic support were examined, together with possible positive outcomes.

Methods: Exploratory approach supported with Van Kaam method for qualitative data analysis. All nurses providing direct care to patients in PICU were included and asked to fill a questionnaire about feelings and consequences regarding the patients' death, and open-ended answers.

Results: Results show nurses changes in emotional state $(93 \%)$, in relationship with patients $(73 \%)$ and with own partner/children (53\%), with colleagues $(40 \%)$ and in physical health (20\%). Nurses report crying, diminished energy, troubled sleep, headache, difficult concentration, physical exhaustion, changes in appetite. Nurses use informal support, but they would use specialistic help if available. Among the positive outcomes, an enhanced purpose in life and a more intense caring for patient towards a dignified death.
Conclusions: Caring for dying babies is a heavy burden for nurses, leading to personal and social consequences on health and work. There is a strong need for specific support to maintain a high quality of care, the ability to establish a therapeutic relationship with patients, providing support to patient's family members and minimize negative consequences for nurses.

\section{0}

\section{HYPOCHOLESTEROLEMIC EFFECT OF A $10 \%$ FISH OIL IV LIPID EMULSION IN PRETERM INFANTS}

\author{
R. D’Ascenzo'1 , L. Angelini ${ }^{1}$, S. D'Egidio', \\ M.P. Bellagamba ${ }^{1}$, A. Bartoli ${ }^{1}$, I. Burattini ${ }^{1}$, \\ P.E. Cogo ${ }^{2}$, V.P. Carnielli ${ }^{1}$
}

${ }^{1}$ Salesi's Children Hospital, Ancona, ${ }^{2}$ University of Padova, Padova, Italy

Background: New lipid emulsions containing fish oil (FO) are recently became available, but there are no informations on their use in preterm infants.

Objective: To compare in preterms a $10 \%$ $\mathrm{FO} / 50 \% \mathrm{MCT} / 40 \%$ soy emulsion (FMS) with a $50 \%$ $\mathrm{MCT} / 50 \%$ soy emulsion (MS).

Design/Methods: Forty seven premature infants were randomized to receive FMS ( $n=23$, GA $202 \pm$ 17 days, BW $1017 \pm 203 \mathrm{~g})$ or $\mathrm{MS}(\mathrm{n}=24$, GA 195 \pm 10 days, BW $1009 \pm 211 \mathrm{~g}$ ). The IV lipid dose

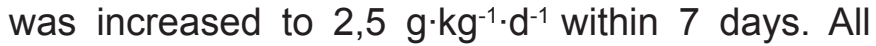
infants were on minimal enteral feeding from birth to d7; they reached full feed on d17. Plasma lipids were determined in cord blood and at d7 and D14 by gas chromatography and mass spectrometry. Routine biochemistry was also performed as part of standard practice. Data were compared using a t-test $(p<0.05)$.

Results: Plasma free cholesterol (FC) and cholesterol esters (CE) are reported below.

\begin{tabular}{|l|c|c|c|c|}
\hline & \multicolumn{2}{|c|}{ Day 7} & \multicolumn{2}{c|}{ Day 14} \\
\hline & FMS & MS & FMS & MS \\
\hline FC $(\mathrm{mg} /$ & $50.4 \pm$ & $58.7 \pm$ & $47.4 \pm$ & $47.4 \pm$ \\
$\mathrm{dl}))$ & $2.7^{\alpha}$ & 2.4 & 3.6 & 2.3 \\
\hline CE $(\mathrm{mg} /$ & $73.7 \pm$ & $89.77 \pm$ & $72.0 \pm$ & $89.4 \pm$ \\
$\mathrm{dl})$ & $7.0^{\alpha}$ & 6.5 & $7.7^{\alpha}$ & 6.5 \\
\hline
\end{tabular}

[FC and CE (mean \pm sem, $\alpha$ pPlasma lipid classes and fatty acids are being analyzed. 